\section{O Pensar-sentir na formação da cidadania contemporânea}

\section{El pensar-sentir en la formación de la ciudadania contemporánea}

\author{
Thinking-Feeling in \\ the Construcction of \\ Contemporary Citizenship
}

\section{Resumo}

0 artigo, resultado de uma pesquisa, tem como objetivo contribuir para compreender os desafios atuais para a educação em cidadania e desenvolver instrumentos capazes de ajudar a fazer frente a eles. Relata-se e discute-se o trabalho de duas áreas de estudo atualmente desenvolvidas no Max Planck Institut for Human Development, em Berlim, e a sua contribuição para a formação da cidadania. Uma delas trata da racionalidade ecológica e do uso de heurísticas para a tomada de decisões em um mundo de incertezas. A outra trata da história das emoções, abordando temas como honra, solidariedade e empatia dentro de uma perspectiva histórica e cultural.

\section{Palavras chave}

Educação em cidadania, racionalidade ecológica, ecologia de racionalidades, heurística, história das emoções

\section{Resumen}

Este artículo, derivado de una investigación, tiene como objetivo contribuir a la comprensión de los desafíos actuales para la educación en ciudadanía y para el desarrollo de instrumentos que ayuden a hacerle frente a esos retos. Se relata y discute el trabajo de dos áreas de estudio actualmente desarrolladas en el Max Planck Institut for Human Development, en Berlín, y su contribución en la formación de la ciudadanía. Una de ellas trata de la racionalidad ecológica y del uso de heurísticas para la toma de decisiones en un mundo de incertidumbres. La otra trata de la historia de las emociones, abordando temas como el honor, la solidaridad y la empatía desde de una perspectiva histórica y cultural.

\section{Palabras clave}

Educación en ciudadanía, racionalidad ecológica, ecología de racionalidades, heurística, historia de las emociones

\section{Abstract}

The purpose of this article, a research product, is to contribute to understand current challenges to citizenship education and to develop new instruments that might help to face those challenges. The study presents and discusses two areas of study developed at the MaxPlanck Institute for Human Development, in Berlin, and their contribution to the construction of citizenship. The first one deals with ecological rationality and the use of heuristics for decision making in an uncertain world. The other one studies the history of emotions, addressing topics such as honor, solidarity and empathy from a historical and cultural perspective.

\section{Key words}

Citizenship education, ecological rationality, ecology of rationalities, heuristics, history of emotions

Fecha de recepción: Agosto 24 de 2015

Fecha de aprobación: Noviembre 20 de 2015 


\section{Introdução}

$\mathrm{N}$ esse artigo proponho uma reflexão à qual fui desafiado por pesquisas recentes no "Instituto Max-Planck para Pesquisa em Desenvolvimento Humano", em Berlim (Alemanha). ${ }^{1}$ Entre outros temas, como o estudo do sistema escolar (Cortina et al., 2008), chamou minha atenção o trabalho de dois grupos de estudos que traziam elementos relevantes para a reflexão sobre cidadania, mais precisamente para a aprendizagem da cidadania. Um desses grupos se ocupa com a "racionalidade ecológica" e, tendo sua base na psicologia, reflete sobre o funcionamento da mente em diferentes áreas da vida humana. Como veremos a seguir, trata-se do conhecimento dos processos de tomada de decisões, desde a escolha dos alimentos até decisões sobre os rumos da sociedade. É inevitável que façamos decisões, maiores e menores, todas elas envolvendo riscos e de incertezas. ${ }^{2}$

0 segundo grupo de pesquisa que despertou a atenção pelo caráter inovador trata da história das emoções ou dos sentimentos. 0 termo "Gefühle", em alemão, tem ainda o significado de sentidos de percepção, o que dá uma conotação mais densa ao conceito. Nossa vida é em boa medida feita pelas emoções e a regra é que as tratemos como fenômenos do inconsciente e, portanto, como parte do inacessível no cotidiano. A expressão "É isso que eu sinto" muitas vezes é dita e entendida como significando o fim da conversa. Embora dialogue com as pesquisas da neurociência (Frevert e Singer, 2011a), o grupo trata das emoções como fenômenos culturais e históricos. 0 mercado, por exemplo, sabe muito bem como se apropriar das emoções e, se necessário, criá-las. Assim o fazem os políticos de direita e esquerda. Ou seja, lidar com as emoções é parte do cotidiano.

0 terceiro pé desta discussão é constituído por uma releitura dos atuais desafios para a cidadania. Trata-se de mais um conceito "cansado" por ser constantemente atropelado na prática, mas ao mesmo tempo ressurge das cinzas como a melhor maneira que temos, até hoje, de criar uma convivência

10 trabalho foi desenvolvido como parte do projeto de "Estágio Sênior" (CAPES, 2012) realizado no Max-Planck-Institut für Bildungswissenschaft, em Berlim, na condição de "guest researcher".

2 Gigerenzer e Voltz (2012) fazem uma distinção entre risco e incerteza. 0 risco se refere ao "mundo pequeno" onde as alternativas são conhecidas, enquanto que a incerteza se refere ao "mundo ampliado" onde a otimização através de cálculo é inviável e onde as decisões são baseadas no que os autores definem como "satisficing". As pesquisas referidas tratam basicamente desse mundo maior, de incertezas. decente. Como sabemos, não pode haver democracia sem cidadania, enquanto pode haver cidadania sem democracia, por exemplo, nos períodos de ditadura. Nesse sentido, a cidadania é um pré-requisito para a democracia. Cidadania, como aqui entendida, trata da construção do sentido do público que, apoiando-nos em Hannah Arendt (2004), tem dois sentidos básicos: poder dizer a sua palavra e ser ouvido. Para ilustrar a que me refiro conto um fato que recentemente vivenciei na Alemanha. Ao comprar o ticket num equipamento eletrônico, faltou em torno de três euros no troco. Eu encolhi os ombros como quem diz "É assim mesmo". 0 amigo que me acompanhava, no entanto, disse que se nós somos honestos com eles (o órgão público do metrô), eles devem ser honestos conosco e temos que reclamar. Resumindo: procurei o guichê, expliquei o que aconteceu, preenchi um formulário com número da conta bancária; no outro dia alguém telefonou para conferir meu endereço e informou o depósito em conta bancária. Foi na Alemanha, mas se esperaria que acontecesse em qualquer parte do mundo. Senti estar sendo tratado como cidadão. Ao comentar com um colega alemão este se apressou a dizer que infelizmente nem sempre é assim.

O objetivo nesse texto é explicitar alguns desafios que o momento histórico atual coloca para a cidadania e que requerem novas aprendizagens e novos instrumentos teórico-metodológicos. Ou, como propõe Edelstein (2006; 2011), novas "competências" para cidadania. Parte-se do pressuposto de que essas competências não são inatas e também não podem ser tomadas como evidentes e estabelecidas. Uma sociedade com grandes mudanças, como a atual, exige permanente atenção aos novos desafios postos para a cidadania. Vejamos, a seguir, alguns deles.

\section{Leitura de mundo e cidadania}

Desde que George W. Bush prometeu fazer uma democracia deste mundo depois do fatídico ataque às torres gêmeas de Nova York (2001), o planeta não se tornou um lugar mais seguro e possivelmente não mais democrático. Há motivos suficientes para que o tema da cidadania esteja na pauta da educação, quem sabe não apenas como mais um tema, mas como uma preocupação central. Neste item pretendo fazer um exercício de olhar para a aprendizagem da cidadania em dois contextos diferentes, Europa e América Latina, sem pretender que seja um estudo comparativo. Este tipo de estudo se tornará cada vez mais necessário na medida em que a própria ideia de cidadania migra de lugar, ou seja, passa a não ser mais estritamente referida ao estado nação. 
Há hoje desafios à cidadania que ultrapassam as fronteiras geográficas. Um deles é a individualização, que é tema recorrente na literatura sociológica e da ciência política (Beck, 1986). Cada vez mais o indivíduo é responsável por "fazer" o seu destino, muitas vezes sem ter o suporte institucional, social e emocional que lhe permita realizar essa tarefa com sucesso. A literatura da exclusão social das últimas décadas retratou esta realidade (Streck, 2009) que se apresenta com características distintas de acordo com os contextos econômicos e sociais. Por exemplo, se na Europa se trata em boa medida da insegurança diante da ameaça de perda de direitos, na América Latina é mais precisamente a perpetuação da dominação e exploração.

Outro desafio é a globalização que traz mudanças profundas no sistema de produção e consumo. São bem conhecidas as denúncias a grandes firmas que se instalam em países com direitos trabalhistas precários ou com um nível salarial baixo para ali fazer a sua produção, com óbvios aumentos da lucratividade. O capital estrangeiro, das companhias transnacionais, que há algumas décadas era criticado como predatório em relação às economias nacionais, hoje é disputado por governos de direita e de esquerda. 0 estado, nesse contexto, vê seu espaço de atuação reduzido (Streek, 2012). 0 processo trouxe também uma muito maior mobilidade - voluntária e forçada das pessoas, tanto assim que o tema dos "migrantes" está na pauta em todos os continentes, que estão implicados como lugares de emigração ou de imigração. Há ainda outras formas de mobilidade, como é o caso dos intercâmbios estudantis, muitas vezes transformados em negócio, mas que fazem parte de uma busca geral de internacionalização da produção acadêmica e do desenvolvimento tecnológico.

A questão ecológica igualmente traz implicações para a cidadania. Não é por menos que a ecologia, hoje, está na linha de frente dos movimentos sociais e faz parte de praticamente todos eles. Não só isso: tornou-se um discurso politicamente correto de empresas e de administrações públicas. A questão ecológica talvez revele de maneira mais clara como as dimensões micro e macro não podem ser dissociadas uma da outra. Começa com a separação do lixo nas casas e se estende à poluição do ar, à contaminação de rios, à pesca predatória em alto mar, entre outros. Isso chama a uma cidadania de caráter planetário até hoje não conhecida. A frustração com as grandes conferências internacionais sobre mudança climática relevam a complexidade e abrangência do tema.
Temos também o que se convencionou chamar de crise da democracia representativa (Rucht, 2010). Os cidadãos não se sentem representados pelas pessoas que periodicamente escolhem para o exercício de funções políticas. Prova disso é que no Brasil são poucas as pessoas que se lembram do nome dos candidatos para o legislativo, em todos os níveis da federação. A falta de credibilidade das instituições políticas não pode ser vista como um mal menor. Um sociólogo grego (Dermetzis, 2012) chama atenção para o fato de que o maior problema na crise grega hoje não é a depressão econômica, mas a depressão de esperança. E uma das causas apontadas para essa depressão da esperança é a acumulação da falta de confiança nos instrumentos políticos.

Por fim, a reterritorialização da política é outro desafio. Prefiro este conceito ao de desterriotorialização (Edelstein, 2006), porque os centros de poder não desaparecem; eles apenas assumem outros papeis e funções dentro do complexo jogo de relações que agora cobre todo o globo. Coloca-se para a aprendizagem de cidadania a possibilidade de desenvolver uma cidadania cosmopolita crítica, onde são possíveis novas formas de identificação, para além de uma exclusiva identidade nacional ou étnica. A União Europeia, hoje, oferece um lugar privilegiado de se observar a construção de uma cidadania multinacional ou transnacional. Há programas educativos (Frevert, 2008) que buscam fomentar essa consciência de pertencimento mútuo, como é o caso de um projeto de jovens para conhecimento da história dos povos que compõem essa comunidade de nações. ${ }^{3}$

$\mathrm{Na}$ América Latina o grande mentor de uma educação cosmopolita é o cubano José Martí. Ninguém mais cubano do que ele; ninguém mais amante de nuestra América, mas também ninguém mais combativo por um mundo justo e pacífico. Em "A história do homem contada por suas casas", publicado na revista para crianças La Edad de Oro (1995) ele conta que cada povo tem o seu jeito de morar e que este jeito é parte de sua história e cultura. E ele conclui com esta bela lição para uma cidadania cosmopolita:

Agora todos os povos do mundo se conhecem melhor e se visitam: e em cada povo há seu modo de construir, conforme faça frio ou calor, ou que sejam de uma raça ou de outra; mas o que parece novo nas cidades não é sua maneira de fazer casas, porém que em cada cidade há casas mouras e gregas e góticas e bizantinas e japonesas, como se começara o tempo feliz em que os homens se tratam como amigos e se vão juntando." (Martí, 2007, p. 167)

3 Ver o programa EU STORY, em WWW.eustory.eu (Acesso em 19.10.2012). 
O título deste tópico propõe ver a própria cidadania como leitura de mundo. A expressão é emprestada de Paulo Freire (2009), de onde ela também traz implícita a ideia de que a leitura do mundo é palavração. É a palavra combinada com ação e essa ação se dá em circunstâncias e condições históricas diferentes. São outros direitos que estão na pauta em diferentes momentos históricos e também são outras as responsabilidades. As lutas pelos direitos civis, como o combate à discriminação racial, a luta pelos direitos políticos como a efetiva possibilidade de participação para além das eleições, a luta pelos direitos humanos e direitos trabalhistas, ou pela ecologia, todos eles fazem parte de uma complexa agenda que se apresenta de maneira diferenciada para pessoas, grupos e povos. E para isso é importante a leitura de mundo para a qual, por sua vez, necessitamos de instrumentos. Os tópicos abaixo apresentam dois desses instrumentos.

\section{Da racionalidade ecológica à ecologia de racionalidades}

A literatura identificada com o "sul" epistemológico vem denunciando há algum tempo que a conquista do território que hoje se conhece como América Latina não se restringiu à conquista de terras ou à exploração das riquezas naturais (Streck \& Adams, 2012). A invasão significou também a ruptura com uma forma de ver e conhecer o mundo, com uma racionalidade. Foi o que Filipe Guamán Poma de Ayla chamou de "Pachakuti", o mundo de pés para cima, um processo que se perpetuou na formação de uma subjetividade colonial. Faz parte do projeto de superação da "colonialidade" (Mignolo, 2004; 2007) o reconhecimento de outras racionalidades, como discutido e exemplificado no livro Epistemologias do sul (Santos \& Meneses, 2009). Trata-se de possibilitar a formação de uma "ecologia de racionalidades" em contraposição à racionalidade que se autodefine como única, por isso, chamada por Boaventura de Sousa Santos (2004) de metonímica.

Um exemplo dessa racionalidade se encontra entre os povos aimara e quéchua na região andina. A expressão aimara Suma Qamaña ou Sumak Kawsay do quéchua equatoriano (traduzidos ao espanhol como buen vivir) ganhou notoriedade nos últimos anos talvez pela conquista da presidência por um descendente indígena, mas não menos porque está posta como sinal de que outras formas de convivência com a natureza e com outras formas de conhecimento são necessárias e possíveis, e que a única saída não está no desenvolvimento tecnológico vinculado a uma racionalidade instrumental. 0 conhecimento, para essas culturas, não pode ser dissociado da relação com a madre-terra, a Pachamama, imbuída de sacralidade, e com a comunidade.

Enquanto isso, estudos da cultura popular apontaram a coexistência de racionalidades diferentes, além da científica, como a simbólica e a sapiencial (Peresson, 1994). Pesquisadores identificaram inteligências múltiplas (Gardner, 1994). As pesquisas das neurociências têm abordado temas como a função do esquecimento, as "ilusões" da percepção, além das doenças do cérebro e formas de prevenção, especialmente em idade avançada (Bonhoeffer \& Gruss, 2011). Ou seja, reconhece-se um quadro complexo do funcionamento da mente humana na lida com a realidade.

No que segue pretendo trazer para a discussão uma linha de pesquisa que procura compreender o processo de tomada de decisões, especialmente em situações de incerteza. Que isso tem a ver com cidadania é mais ou menos evidente. Como diz o diretor deste programa de pesquisa, Gerd Gigerenzer (2012, p. 66) quando fala sobre decisões tomadas sem a devida consideração de risco: "Nós não precisamos apenas de políticos que re-fletem (nachdenken) - nós precisamos de cidadãos que pensam junto (mitdenken)." Isso também remete a uma das preocupações que Paulo Freire (1996) manifesta com o "pensar certo". 0 que se pode aprender de estudos que se ocupam intensivamente com o quê e o como pensamos?

A pesquisa sobre racionalidade ecológica parte do princípio de que a onisciência talvez seja um permanente desejo do ser humano, que muitas vezes age presumindo que a possui. No entanto, para que isso fosse possível deveria haver duas condições que simplesmente não existem: a) um ilimitado poder computacional e b) uma estrutura do mundo determinística. Como essas duas condições não são encontradas no mundo real, também a ideia de otimização, isso é, de checar todas as alternativas possíveis é inviável. Seria como que, para cada decisão, listar os prós e os contra de cada alternativa possível. Pode ser útil em algumas situações, mas geralmente a complexidade e a natureza dos problemas não permite tal cálculo ou este se torna inócuo na hora de tomar a decisão. 0 autor (Gigerenzer, 2012) traz como exemplo a decisão sobre casar ou não casar, ou a decisão de escolha entre possíveis parceiros ou parceiras. Mais eficiente que fazer intermináveis listas, o sujeito poderia jogar uma moeda no ar e, enquanto ela cai, a melhor decisão teria sido tomada. São as chamadas 
"decisões de estômago" que remetem à "inteligência do inconsciente e ao poder da intuição" (Gigerenzer, 2007).

Daí segue que a nossa racionalidade é limitada, vinculada e contextualizada (bounded rationality). A mente funciona como que operando com duas lâminas de uma tesoura: uma delas é a capacidade neurológica e a outra é o ambiente em que operamos, e que condiciona o funcionamento. Para as decisões teríamos uma "caixa de ferramentas", as heurísticas, que são estratégias práticas de tomada de decisão. Essas não são inatas nem fixas, mas têm uma estrutura adaptável ao meio em que atuamos. Exemplos corriqueiros mostram que o senso comum quanto à aplicação de dinheiro pode ser mais vantajoso do que complicados cálculos de especialistas baseados em previsões. Ou que nas apostas de futebol conta pouco estar informado sobre cada jogador e cada possível lance. 0 apostador que pouco conhece e cujo palpite se baseia no nome do time mais popular tem iguais chances de acertar que o especialista que conhece o perfil de cada jogador. Ele estaria usando eficientemente a heurística de "reconhecimento".

Quais são as implicações dessa pesquisa para a cidadania, mais especificamente para a educação em cidadania? A primeira delas é que não se pode cair na armadilha da onisciência, seja de políticos, partidos, teóricos ou experts. A democracia aposta na "sabedoria dos muitos" (Roth, 2011), o que não significa consenso. A sabedoria dos muitos implica em saber lidar com dissensos e conflitos, reconhecendo ao mesmo tempo o caráter provisório da nossa ação e as consequências do que com elas construímos para futuras ações. Uma ditadura, como sabemos, se estende para além da derrubada do ditador. A colônia não terminou com a proclamação das independências na América Latina e na África.

A segunda é que não bastam informações para tomar as melhores decisões. Luria (1968) já se debateu com este problema ao buscar compreender a mente de Shereshevsky, que tinha uma incrível capacidade de guardar uma enorme quantidade de informações, mas que não era capaz de realizar abstrações a partir dos dados “armazenados". Gigerenzer (2010) usa o exemplo do ensino da matemática, que estaria baseada no ensino de certezas, deixando de trabalhar com a probabilidade. 0 resultado são médicos que não sabem interpretar corretamente dados para seus pacientes em relação aos riscos, economistas que agem como se fossem deuses, e cidadãos que não aprenderam a "pensar junto".
A pesquisa revela também a importância da interdisciplinaridade para a aprendizagem em cidadania. A racionalidade ecológica, por partir do princípio de que não existe uma racionalidade não vinculada (unbounded), ajuda a entender porque as pessoas usam caixas de ferramentas diferentes ou usam ferramentas diferentes da mesma caixa. Abrir essas caixas e compreender as ferramentas e o seu uso no cotidiano talvez seja uma forma eficaz de aprender cidadania. Quem sabe chegaremos a entender melhor porque nem todos pensam, votam e agem da mesma forma. Parece abrir-se um caminho para que nos estudos se transite entre o que se busca compreender sobre a racionalidade ecológica e sobre a ecologia de racionalidades.

Por fim, a racionalidade ecológica aponta para uma simplicidade que permite a transparência. 0 perigo, segundo esta teoria, é que métodos complexos se tornam meios de impressionar os outros, enquanto se perdem oportunidades de fazer as coisas de maneira mais eficiente e entender o processo pelo qual fazemos decisões e previsões. Gigerenzer dá como exemplo os sistemas de taxação que na maioria dos países são tão complexos que nem mesmo especialistas da área são capazes de compreendê-los. ${ }^{4} \mathrm{~A}$ racionalidade ecológica, nos termos acima expostos, contém elementos que contribuem para formar cidadãos que saibam pensar junto e lideranças que saibam dos limites de seus projetos e discursos. Poderíamos dizer que o "pensar certo" a que se refere Paulo Freire (1996) não pode prescindir de ferramentas que diversos ramos das ciências estão produzindo.

\section{Emoções sentidas e aprendidas}

Poderia Saturno ter unido a Europa e suas colônias nos trópicos? Na astrologia, Saturno é uma figura complexa que atrai sombras, ruínas, violência, enfermidades e outros tantos problemas. A palavra soturno, que significa triste, taciturno e melancólico, é uma variante de Saturno. 0 que isso teria ver com os dois continentes? Explico abaixo, mas para ilustrar o tema deste tópico trago um exemplo comum à literatura europeia e latino-americana. Honra é hoje uma palavra com pouca carga emocional. Os duelos deram lugar a outras formas de vingança e o fio de bigode deixou de representar qualquer coisa além de um pelo, um cultivo estético ou eventualmente um sinal de masculinidade. Isso não quer dizer que em

4 Em entrevista concedida a mim no dia 23 de outubro de 2012, no Max-Planck Institut für Bildungsforschung. 
alguns momentos pessoas, grupos e nações apelem para a honra ofendida. Mas é uma conotação diferente de outros tempos.

Honra, conforme Ute Frevert (2011a) seria uma das "emoções perdidas". Seu estudo da história das emoções mostra como as mesmas podem mudar devido a traumas, podem receber diferentes nomes e, como é o caso de honra, perder a sua força conotativa e assumir novos sentidos. Em contrapartida, há também "emoções encontradas" como é o caso da empatia ou compaixão, autoestima, sofrimento e pena, solidariedade, entre outros.

Voltemos a Saturno, que Moacyr Scliar (2003) associa com melancolia no seu livro Saturno nos trópicos: a melancolia chega ao Brasil. A melancolia teria sido uma "doença" característica da época da expansão europeia e teria encontrado um clima favorável para o seu cultivo na América Latina. ${ }^{5}$ As condições para a melancolia estariam associadas ao quase extermínio dos indígenas, a uma cultura escravocrata e a perpetuação da desigualdade. A metáfora do labirinto, frequente na época da conquista, ${ }^{6}$ é ainda hoje uma marca da cultura latino-americana. Temos, entre outros, o labirinto de Gabriel García Marquez (O general e seu labirinto, 1990), de Octávio Paz (O labirinto da solidão, 1984) e a expressão maior do que seja o labirinto na obra de Jorge Luis Borges (2001, p. 31).

\section{Não haverá nunca uma porta. Estás dentro \\ E o alcácer abarca o universo \\ E não tem nem anverso nem reverso Nem externo muro nem secreto centro. Não esperes que o rigor de teu caminho Que teimosamente se bifurca em outro, Que obstinadamente se bifurca em outro, Tenha fim. É de ferro teu destino \\ Como teu juiz. Não aguardes a investida Do touro que é um homem e cuja estranha Forma plural dá horror à maranha De interminável pedra entretecida.}

Encontramos um estudo da melancolia europeia no citado livro de Ute Frevert. Emblemática, para a época dos "descobrimentos", é a gravura "Melencolia" de Albrecht Dürer, de 1514, onde uma figura feminina medita, numa atitude que se situa entre desolação e expectativa, em meio aos novos instrumentos da época, mais ou menos como que dizendo: "O que vou fazer com isso?" A palavra melancolia, que ganhou

5 Ele fala especificamente do Brasil, mas sua análise se aplica, com variantes, a toda a América Latina.

6 Veja-se, por exemplo, The Labirinth of the World, de J.A. Comenius. proeminência na idade moderna, era atribuída à produção da bile e acompanhava-a a tristeza, o entusiasmo e a falta de envolvimento. Foi sucedânea da acedia dos tempos medievais, vista como um poder demoníaco que poderia vir a cada momento e tomar conta da pessoa, infligindo tédio e falta de vontade. Especialmente entre os monges, esse era um pecado grave porque lhes tirava o ânimo de ler e de rezar. Hoje não se fala mais nem de acedia como pecado, nem de melancolia como problema fisiológico, mas de depressão como estado psíquico a ser tratado com medicamentos ou psicoterapia. Ou seja, este é o argumento da autora, as maneiras de "sentir" são ressignificadas na história, podem receber outros nomes e ser atribuídas a outras causas.

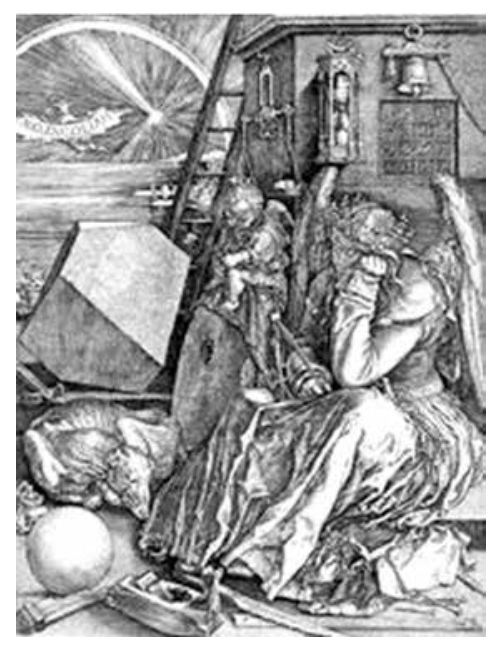

Figura 1. Albrect Dürer, 1514

Ao contrário do que às vezes se supõe, as emoções ocupam um lugar central na modernidade. Frevert (2011a) ilustra isso com o estudo das emoções no capitalismo, um campo supostamente regido por uma lógica fria e instrumental dirigida ao lucro. Ultimamente essa percepção mudou e a "inteligência emocional" (Coleman, 1998) passou a fazer parte das competências de gestão em muitas empresas. Mas essa relação não é de agora. A autora volta à história e relata que o professor de Adam Smith havia cunhado, em 1728, o termo "economia emocional" no Ensaio sobre a natureza e conduta das paixões e afetos. Com interpretações diferentes, hoje as emoções são amplamente reconhecidas no campo da produção, do consumo e propaganda, e - ela acrescenta - da solidariedade e do capital social. Do lado dos trabalhadores a solidariedade, historicamente, significou a união para lutar pelos seus direitos, enquanto que do lado dos empresários poderia significar caridade ou, atualmente, a responsabilidade social. 
No campo da educação as emoções ganham um destaque especial na obra de Rousseau, um dos expoentes do Iluminismo. Poderia haver uma coerência entre a racionalidade iluminista e a valorização das emoções? Rousseau critica uma racionalidade fria, não revestida de emoção, que seria uma expressão de mentes frágeis e pequenas. Também o educador deveria ter a competência de conhecer as paixões de seus alunos. Eis as qualidades do mestre: "Um grande interesse em conhecê-los, uma grande imparcialidade para julgá-los, um coração suficientemente sensível para compreender as paixões humanas e suficientemente calmo para não experimentá-las." (Rousseau, 1995, p. 323). 0 fato de juntar imparcialidade de julgamento com o coração sensível para conhecer as paixões dos alunos sugere o reconhecimento das emoções como parte constitutiva do projeto educativo moderno. Tanto a razão iluminada quanto a valorização das emoções fazia parte da possibilidade de criar um novo ser humano para uma nova sociedade. A "educabilidade", reconheceram Rousseau e seus contemporâneos, não poderia abrir mão de formar as emoções. Se voltarmos mais atrás na história, veremos que também Comenius (1957) falava de educar a mente, o coração e as mãos. 0 que é diferente em Rousseau é que a educação é desvinculada, em princípio, de uma educação religiosa, sendo referida à natureza humana que gera o sentimento de amor de si e se transforma num sentimento de piedade e compaixão para com o outro. Faz parte do projeto pedagógico "gerir" as emoções ou, se desejamos, educá-las.

Na América Latina, vemos as emoções presentes de forma muito forte na proposta educativa de dois de seus maiores expoentes. No revolucionário José Martí, é a honra da pátria ferida que reflete a honra a todos os homens e mulheres. No Centro de Estudos Martianos, em Havana, está gravada a célebre frase: "Honrar honra". Ou seja, há uma promessa de respeito recíproco entre pessoas que têm este sentimento e comportamento. Na sua revista para crianças, $L a$ Edad de Oro, o cultivo da honra aparece desde a introdução: "Assim queremos que os meninos de América sejam: homens que digam o que pensam, e o digam bem: homens eloquentes e sinceros" (Martí, 2007, p. 140). No parágrafo seguinte complementa, dizendo que as meninas deveriam saber o mesmo que os meninos.

Outros sentimento que perpassa a sua obra e se revela sobretudo importante para a educação é a ternura, palavra que depois se tornará imortalizada na célebre frase de Che Guevara: "Hay que endurecerse siempre, pero sin perder la ternura jamás." Ternura, para José Martí, tem a ver com a capacidade de degelar o sangue coagulado nas veias de nuestra América pelos séculos de dominação. A transmissão de técnicas modernas será insuficiente para a construção de novas nações. Por isso: "Eis aqui, pois, o que tem de levar os mestres pelos campos. Não somente explicações agrícolas instrumentos mecânicos; sim a ternura, que faz tanta falta e tanto bem aos homens" (Martí, 2007, p. 43)

Também em Paulo Freire a emoção desempenha um papel importante na prática e na teoria. Para ele, a razão e as emoções são parte de um mesmo corpo que pensa, que sente e que age. 0 corpo, sempre encharcado de cultura, se transforma também no lócus do ensinar e aprender.

Gostaria desde já de manifestar minha recusa a certo tipo de crítica cientificista que insinua faltar rigor no modo como discuto os problemas e na linguagem demasiado afetiva que uso. A paixão com que conheço, falo ou escrevo não diminuem o compromisso com que denuncio ou anuncio. Sou uma inteireza e não uma dicotomia. Não tenho uma parte esquemática, meticulosa, racionalista e outra desarticulada, imprecisa, querendo simplesmente bem ao mundo. Conheço com o meu corpo todo, sentimentos, paixão. Razão também (Freire, 2006, p. 18).

Basta recordar três ideias chaves que caracterizam sua produção nos últimos anos, duas delas referidas em títulos de livros. A primeira delas é a Pedagogia da esperança (1992), onde a esperança é vista como uma condição ontológica e que por isso precisa ser "educada". Sem essa educação, ela pode virar desesperança que leva à inação ou ao desespero. A outra é a Pedagogia da Indignação (2008) título de um livro póstumo editado por Ana Maria Araújo Freire. Trata-se da capacidade de se insurgir contra situações de opressão e "sulear" essa indignação para as marchas pelos inéditos viáveis que Paulo Freire sonhava em ver pelo mundo. Por fim, a amorosidade (Fernandes, 2010, p. 37) como critério de qualidade das relações humanas que se manifesta na capacidade de diálogo.

\section{Aprender cidadania: emoções e racionalidade na ação}

Tive como pressuposto nesta revisão que as pesquisas sobre racionalidade ecológica e sobre a história das emoções podem contribuir para a educação em cidadania. 0 conectivo em é usado intencionalmente para conotar que se está, por definição, lidando com cidadãos e não com alguém que precisa ser incluído na cidadania. Estes podem estar, isso sim, incluídos 
de forma subalternizada. Inicio a conclusão, trazendo dois exemplos de recentes pesquisas para reunir os tópicos antes considerados separadamente. 0 propósito é também verificar como esses conceitos podem se traduzir na prática e servir para melhorá-la.

Os carrinheiros de Curitiba: Numa reunião de pesquisa um carrinheiro disse com muito orgulho que estava indo à universidade para dar uma palestra. Uma notícia dessas, em primeiro lugar, emociona positivamente quem costuma ver homens e mulheres puxando o seu carrinho pelas ruas em busca do "ouro", como alguém disse. Na realidade, trata-se de uma garimpagem com muitas surpresas como revela uma espiada no pequeno espaço destinado a cada indivíduo ou família no galpão de reciclagem. A ideia que esse carrinheiro passou é que "agora somos gente." Essa é a emoção que se pode sentir na sua expressão. Ao mesmo tempo, esse homem havia aprendido a manejar melhor as ferramentas de seu estoque de heurísticas, ou seja, de estratégias de adaptação crítico-realista ao seu ambiente. De outra perspectiva, poderiam ser vistas também como estratégias de resistência e de não adaptação a uma inclusão subordinada. Os cursos sobre economia solidária e o engajamento em ações e discussões políticas haviam propiciado um ambiente para desenvolver uma racionalidade que combina uma visão realista de sua atividade com uma perspectiva de sociedade e de futuro.

Os cidadãos no orçamento participativo: Quem participa de assembleias do orçamento participativo geralmente vem como uma agenda: conseguir algum recurso para a escola de sua comunidade, a construção de uma estrada, o apoio a alguma entidade, entre outros. Isso não significa que essa "demanda" de um indivíduo ou de um grupo entre como prioridade de uma assembleia. Dá-se ali um processo de aprendizagem onde aparecem misturados sentimentos de competição, de solidariedade, de frustração por derrotas e satisfação por vitórias. Poucas vezes essas emoções são expressas, mas elas são perceptíveis. Em termos de "racionalidade ecológica" há o aprendizado de um ajustamento das duas lâminas compostas pela capacidade de computação e pelo ambiente através de negociações, de avaliação de riscos e de possibilidades inerentes a cada uma das demandas. Uma contribuição dessa linha de pesquisa para a formação da cidadania consiste em ajudar a compreender o desenvolvimento de processos cognitivos eficazes do ponto de vista da ação coletiva e emancipatórios do ponto de vista ideológico.
Com esses breves exemplos desejo mostrar que na formação da cidadania esses dois elementos racionalidade ecológica e emoções - se encontram na práxis, enquanto uma ação refletida e sentida, ou sentipensada, parafraseando Fals Borda (2009). É na ação que se decidem os valores, muitas vezes implícitos. A racionalidade ecológica procura superar uma visão puramente instrumental da razão (Simon, 1990, p. 191). ${ }^{7}$ Por ser uma racionalidade na ação (Gigerenzer \& Sturm, 2012), ela também busca superar a tradicional divisão da tarefa entre filósofos, a quem caberia definir para que "serve" a razão, e de psicólogos, a quem caberia dizer como a mente funciona. Também as emoções não podem ser julgadas à parte da ação. Uma grande frustração pode levar a uma reação ativa para mudança ou à apatia. É na ação que será possível verificar o seu "valor."

Uma segunda conclusão diz respeito à educação das emoções e da racionalidade. 0 movimento dos indignados $^{8}$ não tem uma relação direta com a pedagogia da indignação, de Paulo Freire, mas o nome do movimento sugere a conexão com a educação. Tal como a pedagogia da esperança, o desafio pedagógico consiste em fazer com que esta indignação não seja domesticada e seja direcionada para ações coletivas com o potencial de gerar as mudanças necessárias. 0 que as pessoas que vão para rua desejam não é apenas manifestar seus sentimentos. Elas clamam pela possibilidade de "pensar junto" o seu destino. Abremse, com base nos estudos resenhados, perspectivas para compreender num exercício interdisciplinar a dinâmica dos processos cognitivos e afetivos nas culturas e, respectivamente, adequar as estratégias pedagógicas para a formação da cidadania.

\section{Referências}

Arendt, H. (2004). A condição humana. Chicago: The University of Chicago Press.

Beck, U. (1986). Risikogesellschaft: Auf dem Weg in eine andere Moderne. Frankfurt: Shurkamp Verlag.

7 "Nós vemos que a razão é totalmente instrumental. Ela não pode nos dizer para onde vamos; na melhor das hipóteses, ela pode nos dizer como chagar até lá. É uma arma de aluguel que pode ser usada para quaisquer objetivos que tenhamos, bons ou maus" (Tradução minha).

8 Movimento iniciado na Espanha em 15 de maio de 2011 e que suscitou manifestações contra as políticas econômicas e por reformas políticas em vários países. 
Bonhoeffer, T., e Gruss, P. (Hrsg.) (2011). Zukunft Gehirn: Neue Erkenntnisse, neue Herausforderungen. Ein Report der Max Planck Gesellschat. München: Verlag Beck.Borges, J. L. (2001). Elogio da sombra. Sao Paulo: Globo.

Coleman, D. (1998). Working with Emotional Intelligence. New York: Bantam Books.

Coménius J. A. (1957). Didáctica Magna (3. ed.). Lisboa: Fundação Calouste Gulbenkian.

Coménio, J. A. (2012/1631). The labirinth of the World and the Paradise of the Heart. Available at http://users.ox.ac. uk/ tayl0010/labyrint/labyrinth_frame.html

Cortina, K.; Baumert, J.; Leschinsky, A.; Mayer, K.;Trommer, L. (2008). Das Bildungswesen in der Bundesrepublik Deutschland. Hamburg: Rohworlt.

Dermetzis, N. et al. (October 2012). Critical Emotions in the Mid of Crisis. Paper presented at $4^{\text {th }}$ Midterm Conference of the ESA RN Sociology of Emotions, 11-13 October 2012. Max-Planck Institute for Human Development, Berlin.

Edelstein, W. (2006). Kompetenzen für die Zivilgesellschaft. In: Innovative Schule Entwckeln: Kompetenzen, Práxis uns Vision. Pädagogische HOchschule Heidelberg. Band 47.

Edelstein, W. (2011). Education for Democracy: Reasons and Strategies. European Journal of Education, 1(46), Part II.

Fals Borda, 0. (2009). Uma sociologia sentipensante para América Latina (Antología y presentación de Víctor Manuel Moncayo). Bogotá: Siglo Del Hombre Editores y CLACSO.

Fernandes, C. (2010). Amorosidade. In: Streck, D. et al. (Orgs.). Dicionário Paulo Freire (2. ed. pp. 37-39). Belo Horizonte: Autêntica.

Freire, P. (1992). Pedagogia da esperança. São Paulo: Paz \& Terra.

Freire, P. (1996). Pedagogia da autonomia: saberes necessários à prática educativa. São Paulo: Paz e Terra.

Freire, P. (2006). À sobra dessa mangueira. São Paulo: Olho d'água.

Freire, P. (2008). Pedagogia da indignação: cartas pedagógicas e outros escritos. São Paulo: UNESP.

Freire, P. (2009). A importância do ato de ler em três artigos que se complementam (50. ed.). São Paulo: Cortez.
Frevert, U. (2008). How to become a Good European Citizen: Present Challenges and Past Experiences. In: Georgi, V. B. (Ed.), The Making of Citizens in Europe: New Perspectves on Citizenship Education (pp. 37-51). Bonn: Bundeszentrale für politische Bildung.

Frevert, U. (2011a). Emotions in History: Lost and Found. Budapest/New York: Central European University Press.

Frevert, U. (2011b). Gefühle und Kapitalismus. In: Budde, G. (Hg.), Kapitalismus: Historische Annährungen (pp. 50-72). Göttingen: Vandenhoek \& Ruprecht.

Frevert, U. (2011c). Gefühlswissen: Eine lexikale Spurensuch in der Moderne. Frankfurt: Campus Verlag.

Frevert, U., e Singer, T. (2011). Empathie und ihre Blockaden: Über soziale Emotionen. In: Bonhoeffer, T., e Gruss, P. (Hrsg.), Zukunft Gehirn: Neue Erkenntnisse, neue Herausforderungen. Ein Report der Max Planck Gesellschat. München: Verlag Beck García Márquez, G. (1990). O general e seu labirinto (3. ed.). Rio de Janeiro: Record.

Gardner, H. (1994). Estruturas da mente. Porto Alegre: Artmed.

Gigerenzer, G. (2006). Bounded and Rational. In: Sainto, R. J. (Ed.). Contemporary debates in cognitive science (pp. 115-133). Oxford, UK: Blackweel.

Gigerenzer, G. (2007). Bauchentscheidungen: Die Intelligenz des Unbewusten und die Macht det Intuition. München: C. Betersmann Verlag.

Gigerenzer, G. (Dezember 2010). Wie wening wir über Wirschaft wissen. (Interview to Anja Müller). Handelsblatt, Montag, 13, 22-23.

Gigerenzer, G. (März, 2012). "Werfen Sie einfach eine Münze..." Psychologie Heute, p. 64-70.

Gigerenzer, G., e Sturm, P. (2012). Syntese, 187:243-268. Springer Science+Business Media.

Klibansky, R. (2005). Saturn and melancholoy; studies in the history of natural philosophy, religion. Ann Arbor, Michigan: University of Michigan Library.

Luria, A. R. (1968). The mind of a mnemonist. New York: Basic Books.

Martí, J. (1995). La Edad de Oro (2. ed.). La Habana: Pueblo y Educación.

Martí, J. (2007). Educação em Nossa América: Textos selecionados. Organização e apresentação de Danilo Streck. Ijuí: Unijuí. 
Mignolo, W. D. (2004). Os esplendores e as misérias da "ciência": colonialidade, geopolítica do conhecimento e pluri-versalidade epistêmica. In: Santos, B. de S. (Org.), Conhecimento prudente para uma vida decente: um discurso sobre as ciências revisitado (pp. 667-709). São Paulo: Cortez.

Mignolo, W. D. (2007). La idea de América Latina. La herida colonial y la opción decolononial (Traducción: Silvia Jawerbaum y Julieta Barba). Barcelona: Gedisa Editorial.

Paz, O. (1984). O labirinto da solidão (2. ed.). Rio de Janeiro: Paz e Terra.

Peresson, T. (S.D.B.), M. (1994). Educar desde las culturas populares. Cuadernos de Educación y cultura.

Roth, R. (2011). Bürgermacht: Eine Streitschrift für mehr Partizipation. Hamburg: Kürber-Stiftung.

Rousseau, J.-J. (1995). Emílio ou Da educação. São Paulo: Martins Fontes.

Rucht, D. (Mai 2010). Engament im Wandel: Politische Partizipation in Deutschland.. http://bibliothek.wzb. eu/wzbrief-zivilengagement/WZBriefZivilengagement012010_rucht.pdf

Santos, B. S., e Meneses, M. de P. (Orgs) (2009). Epistemologias do Sul. Coimbra: Edições Almedia.
Santos, B.de S. (2004). Para uma sociologia das ausências e uma sociologia das emergências. In: Santos, B. de S., Conhecimento prudente para uma vida decente: um discurso sobre as ciências revisitado (pp.777-819). São Paulo: Cortez.

Scliar, M. (2003). Saturno nos trópicos: a melancolia chega ao Brasil. São Paulo: Companhia das Letras.

Simon, H. A. (1990). Alternative visions of rationality. In: Moser, P. K. (Ed.), Rationality in Action: contemporary approaches (pp. 189-206). Cambridge: Cambridge University Press.

Streck, D. R. (2009). Da pedagogia do oprimido às pedagogias da exclusão: um breve balanço crítico. Educação \& Sociedade (Impresso), 30, 539-560.

Streck, D. R., e Adams, T. (2012). Pesquisa em Educação: os movimentos sociais e a reconstrução epistemológica num contexto de colonialidade. Educação e Pesquisa (USP. Impresso), 38, 243-258.

Streek, W. (2012). Der Staat hat immer weniger Handlungsspielraum (Interview Ralf Groetger). Max-Planck Forschung, 3, 34-39.

Volz, K., \& Gigerenzer, G. (July 2012). Cognitive processes in decisions under risk are not the same as in decisions under uncertainty. Frontiers in Neuroscience, 6 (article 105), 1-6. 